\title{
Late Neoliberalism and its Discontents in the Economic Crisis
}

\author{
POR Carlos Alves* \\ * Universidade Nova de Lisboa, Portugal
}

Porta, D. D., Andretta, M., Fernandes, T., O’Connor, F., Romanos, E., Vogiatzoglou, M. (2017). Late Neoliberalism and its Discontents in the Economic Crisis: Comparing Social Movements in the European Periphery. Cham: Palgrave Macmillan

Late Neoliberalism and its Discontents in the Economic Crisis, com o subtítulo Comparing Social Movements in the European Periphery, edição Palgrave Macmillan, ainda sem tradução disponível em português, resulta de um interesse simultaneamente teórico e empírico. Intermediário entre a investigação em torno dos movimentos sociais (2017: 2) e a economia política, desenvolve-se sob Social Movements in Times of Austerity (Polity, 2015) de Donatella della Porta que enfatizava as semelhanças entre os movimentos sociais suscitados pelo neoliberalismo tardio (neoliberalismo na Grande Recessão). Visa perceber de que modo as especificidades das crises política e financeira afetaram os países da Europa periférica.

Alicerçado em casos de estudo, privilegiando a evolução da crise sócio económica e os seus descontentamentos, o seu intuito empírico é apurar de que modo as tradições dos movimentos sociais interagem com as características contextuais dos protestos antiausteridade nos países europeus mais afetados pela crise financeira e as políticas de austeridade que se lhe seguiram. Consubstancia-se metodologicamente numa triangulação entre fontes documentais e entrevistas a ativistas (2017: 30), numa abordagem comparativa, considerando as diferenças reconhecíveis entre casos similares, histórica e geograficamente próximos.

Ao incluir no estudo não apenas a Europa do Sul, seguindo a tendência de a reconhecer como contendo quatro países principais, mas igualmente a Islândia, Irlanda e Chipre, procura-se identificar as semelhanças entre casos geograficamente distantes, ocupando posições idênticas na crise do neoliberalismo tardio (2017:30). 
Na sua introdução (capítulo 1) Donatella della Porta destaca os tipos de crises a que os movimentos sociais tiveram de reagir enquanto se revelavam na UE e debruça-se sobre as respostas políticas à crise e consequências sociais e políticas, definindo os desafios do contexto político para os movimentos sociais na Grande Recessão.

Salientam-se as diferenças transnacionais e da evolução das crises, com particular atenção para a periferia europeia, ou seja, a zona mais afetada e, simultaneamente, a área onde os movimentos sociais contra a austeridade estiveram mais ativos, embora em modos distintos.

O objetivo é o de estabelecer uma visão dinâmica do protesto em tempos de austeridade, concebendo-a como: relacional, construída sob as interações entre os diferentes atores; construída, uma vez que é filtrada pela construção social da realidade externa; e emergente, uma vez que se desenvolve a partir de conjunturas críticas que reduzem o poder dos constrangimentos estruturais, aumentando o poder de ação.

Se noutras obras (della Porta, 2015) a autora evidenciou as semelhanças dos movimentos da periferia europeia em contraste com os do resto da Europa, agora foca-se, sobretudo, na comparação interna dos países mais severamente afetados pelas crises. O objetivo é o de fazer sobressair as diferenças quanto à sua solidez e alcance dos movimentos sociais e compreendê-los em termos de três conjuntos de dimensões: 1) as caraterísticas específicas da crise sócio económica e as suas consequências em termos de potencial de mobilização; 2) as reações políticas à mesma, no que pode ser definido como ameaças e oportunidades políticas; e 3) as estruturas e culturas do movimento social que individualizam cada país.

É expectável que intensidades e características distintas das crises políticas e sócio económicas afetem a intensidade e características da oposição à austeridade, provocando atributos antissistema ou contramovimento e que uma comparação transversal aos países selecionados quanto às crises e descontentamento associado, na periferia europeia, clarifique estas relações, na sua evolução dinâmica.

Uma vez que a transversalidade analítica dos países está relacionada com uma análise transnacional, a apresentação dos casos de estudo segue o timing do desenrolar das crises, começando pela Islândia continuando pela Grécia, Irlanda, Espanha, Portugal, Itália e Chipre.

Embora considerando as características gerais dos protestos antiausteridade, já referenciadas (della Porta, 2015), são visíveis diferenças no computo dos protestos, nomeadamente no que diz respeito ao framing, reportório de ação e modelos organizacionais. As expetativas iniciais são de que isto esteja enraizado nas culturas e estruturas de vários movimentos domésticos, bem como adaptando-se às características das crises políticas e sócio económicas. Que as estruturas organizacionais se identifiquem com uma tradição mais horizontal em Espanha e Grécia, bem como Irlanda e Chipre e que o equilíbrio entre as tradições libertárias de esquerda e direita podem variar, com discursos sobre as classes mais enraizados na Europa do Sul do que na Islândia e Irlanda.

Espera-se, ainda, que as greves e marchas variem de país para país, com estratégias externas mais tradicionalmente enraizadas na Grécia ou Espanha do que em Itália ou Portugal. 
Enquanto as oportunidades políticas têm sido consideradas relevantes quer como sendo condições (institucionais) estáveis ou contingentes, a atenção para com as políticas neoliberais nas pós democracias é de importância maior para compreender de que modo os movimentos sociais se conseguem adaptar e questionar uma situação caracterizada por elevados níveis de desconfiança institucional, declínio das organizações institucionais do consenso político e despojamento das competências políticas, ou seja, uma crise de responsabilidade (2017:30).

Há muito tempo considerados "children of affluent times" ou pelo menos "of times of opening opportunities" (2017: 1), a literatura relativa aos movimentos sociais tem-se focado nestes em períodos de prosperidade, particularmente os que se desenvolvem em democracias avançadas, assistência social próspera e partidos políticos e instituições representativas bem implantadas (2017:262).

Os protestos da Grande Recessão desafiam esta tendência, desenvolvendo-se em momentos de decréscimo de oportunidades tanto no plano económico como político e sob condições de profunda recessão, restrições no estado social e deslegitimação das instituições representativas (2017: 262).

Ora, isso levanta a questão se continuam os estudos dirigidos aos movimentos sociais a ser úteis para o entendimento destes movimentos de períodos conturbados (já levantada por Donatella della Porta) ${ }^{[1]}$.

A resposta positiva dos autores defende a necessidade de construir pontes entre a política de contestação (contentious politics) com outros campos (economia política [2017:3]), uma vez que as reflexões sobre as tensões intrínsecas ao capitalismo democrático são importantes para compreender o neoliberalismo e as suas crises (2017:2).

Estabelece-se uma arqueologia da crise: de bancária, a crise da dívida pública, de investimento, a crise social afetando a Europa periférica (2017:8).

O capítulo dois, dedicado à Islândia (primeiro país europeu diretamente afetado pela crise financeira de 2008), denominado Iceland's Mobilization in the Financial Crisis (pp. 39-64), de Markos Vogiatzoglou, examina a onda de mobilização relativa à crise financeira islandesa.

A sua precocidade no que se tornaria mais tarde uma onda de antiausteridade transversal à Europa e não só, bem como os assuntos específicos que antecipou, conferem-lhe especial importância (2017:62).

O capítulo três, The Presence and Absence of Protest in Austerity Ireland (pp. 6598) de Francis O'Connor é dedicado à Irlanda: o primeiro país da União Europeia a sucumbir à crise financeira global em 2008. Tal como na Islândia, a crise foi alimentada pelo enfraquecimento do sistema financeiro (2017:276).

Os protestos limitados durante o pico da crise cresceram a partir da mesma. Contrariando posições pouco fundamentadas, os anos de austeridade irlandeses testemunharam uma enorme agitação política e social. O protesto (não ausente) desenvolveu-se a um ritmo próprio de algum modo independente dos outros países (PIIGS). Permaneceu pacífico, alicerçado numa inconsistência política e com um discurso orientado localmente (2017: 90-91).

1. Cf. <https://www.opendemocracy.net/wfd/donatella-della-porta/late-neoliberalism-and-its-discontents $>$. 
O capítulo quatro, Turbulent Flow: Anti-Austerity Mobilization in Greece (pp. 99129) de Markos Vogiatzoglou examina as formas que a mobilização antiausteridade tomou entre, 2010-2014, na Grécia, reflexo da crise financeira global de 2008 que chegou à Grécia no início de 2010.

Apresentam-se as caraterísticas principais do protesto antiausteridade grego no campo político, societal e dos movimentos sociais. Argumenta-se que o caminho que a mobilização tomou reflete não só a tradição estabelecida pelas organizações dos movimentos sociais pré-existentes mas, também, permitiu a experimentação e desenvolvimento de novas práticas dos movimentos sociais e formas organizacionais. O papel das conjunturas críticas foi particularmente importante para acolher os desenvolvimentos observados.

Eduardo Romanos em relação à situação vivida em Espanha, no capítulo cinco, Late Neoliberalism and Its Indignados: Contention in Austerity Spain (pp. 131-167) apresenta uma visão geral sobre o ciclo de protesto, focando-se no contexto sócio económico, nas oportunidades políticas, nas formas de ação e organização e os objetivos, identidades e enquadramento dos ativistas.

Tal como na Grécia, as respostas políticas à crise em Espanha afetaram dramaticamente a vida quotidiana dos cidadãos. À semelhança do que sucedeu na Irlanda, a crise não estava inicialmente relacionada com a dívida soberana: ao invés, a dívida pública aumentou quando a Espanha teve de responder ao desemprego crescente, ligado ao colapso do mercado imobiliário e a queda da receita.

A 15/05/11 uma convocatória para marchas de protesto em Espanha despoletou um movimento social (Indignados), com capacidade de mobilização, visão e impacto sem precedente na história recente do país (2017:131). O protesto deu início a uma longa e forte onda de contestação que inovou tanto o movimento social como as arenas políticas tradicionais (2017:263).

Em Late Neoliberalism and Its Discontents: The Case of Portugal, capítulo seis, de Tiago Fernandes, dedicado a Portugal, salienta-se o caráter peculiar do caso português, devido ao volume bastante elevado de protesto registado no contexto do sul europeu (aumentando regularmente durante o período de austeridade) e, ainda, a existência de movimentos de protesto que tendencialmente formaram organizações coesas, criaram coligações estáveis abrangentes, tomaram uma amplitude nacional e estabeleceram alianças com sindicatos e partidos políticos de esquerda.

Descrevem-se os traços principais do movimento social português e dinâmicas de protesto durante a Grande Recessão, cuja singularidade é explicável por duas dimensões inter-relacionadas: 1) o impacto da crise (os efeitos da recessão agravaram-se com a assinatura de um memorando de entendimento entre o país e as organizações credoras) no bem estar da população foi menos severo do que na maior parte dos países sul europeus, nomeadamente o risco de pobreza (as mudanças quotidianas mais dramáticas foram facilitadas pelo Estado Social cujas bases remontam aos anos que se seguiram, imediatamente, ao 25 de Abril), embora como consequência a crise tenha conduzido ao empobrecimento. Os efeitos políticos da crise, visíveis em Portugal, foram-no numa escala menor do que na Grécia e Espanha (2017:288); 2) o 
contexto político e institucional facilitou a disponibilidade de aliados, voz e recursos para os movimentos sociais.

Apesar do corpo de investigação existente mostrar que o protesto dos cidadãos e a formação de movimentos sociais serem menos propensos a acontecer em condições de recessão económica, deve considerar-se a variação no que a isto diz respeito.

Massimiliano Andretta no capítulo sete, Neoliberalism and Its Discontents in Italy: Protests Without Movement (pp. 201-241), dedicado a Itália, refere que as descobertas empíricas do capítulo revelam a importância da estrutura de oportunidades políticas, que funcionou como um filtro entre as ameaças ou descontentamentos e a mobilização de protesto na tradição italiana dos movimentos sociais (2017:232).

Identificam-se as características principais da mobilização antiausteridade, salientando-se a prevalência de uma lógica de ação coletiva fragmentada e conduzida por velhos atores. A primeira parte do capítulo resume as condições sócio económicas e políticas sob as quais surgiram os protestos antiausteridade. Segue-se a análise das características principais dos protestos e de que modo estes espelham os constrangimentos políticos externos.

Pretende-se 1) enquadrar a mobilização antiausteridade no seu contexto económico social e político, 2) descrever as suas características principais e 3) explicar a escassez de resultados políticos.

Reconhece-se o predomínio de greves legais, manifestações com sindicatos, organizações tradicionais enquanto atores coletivos e, à semelhança do caso português, o crescimento da defesa dos direitos dos cidadãos e de uma política de contestação mais reativa do que proativa.

O impacto reduzido deve-se a: 1) configuração política dos governos face à crise económica; 2) estrutura da oportunidade política alargada e 3) o tipo de sociedade civil.

No capítulo oito, Cyprus' Explosion: Financial Crisis and Anti-austerity Mobilization (pp. 243-259), Markos Vogiatzoglou examina as condições sócio económicas e políticas que caraterizaram o caso cipriota, focando-se nos formatos organizacionais, principais atores dos protestos, framing, detendo-se na crise cipriota bem como na limitada mobilização antiausteridade.

Embora o colapso financeiro tenha tido um impacto importante na economia cipriota, e não obstante os esforços dos movimentos sociais locais para estabelecer alianças com outros grupos, de modo a conter as medidas de austeridade, a resistência às consequências da crise foi limitada e escassa (2017: 244).

O memorando cipriota não desencadeou uma resistência popular tão intensa como nos países europeus onde a troika interveio devido: à relativa fraqueza da sociedade civil; ao enquadramento temporal sob que se desenvolveram os protestos (as mobilizações antiausteridade cipriotas foram as últimas a emergir na Europa (2017:255); à forte presença das organizações (embora marginais) de esquerda pré existentes que condicionaram a emergência de novos atores de protesto com os quais a sociedade se pudesse identificar (2017:244). 
As características dos movimentos sociais, embora não sendo descartáveis, não podem ser identificadas como responsáveis pelo outcome reduzido proveniente das mobilizações.

Sobressai uma reduzida presença de atores não políticos emergentes e de atores políticos semelhantes ao Podemos em Espanha ou em ascensão como o Syriza na Grécia (2017: 254).

Atribui-se à fraca presença de atores não políticos emergentes a explicação parcial da incapacidade do movimento social cipriota se expandir e tornar mais abrangente mais o facto de que os governos que recorreram à assistência da troika provinham de ambos os lados do espectro político quer seja centro direita ou esquerda (2017: 254).

O capítulo encerra com uma análise e discussão do que pode ser considerado o elo mais fraco na cadeia dos protestos antiausteridade ocorridos na Europa após a crise financeira de 2008 (2017:244).

Ressalta nesta obra a convicção de que o neoliberalismo tardio teve características semelhantes por toda a Europa, mas que se a recessão teve efeitos generalizados não impôs convergência entre países (2017:261). Da crise derivaram caraterísticas, desenvolvimentos e timings nacionais diferenciados e essas condições contextuais refletiram-se nos movimentos que se mobilizaram (2017:279). Genericamente o descontentamento crescente traduziu-se, embora não literalmente, numa deslegitimação política das instituições e partidos existentes no poder e defesa dos direitos da cidadania e com eles da democracia (2017:279-280).

Contrariamente às expetativas presentes em muita da literatura sociológica, os movimentos mais transformativos surgiram onde e quando a crise se agudizou (2017:268), salientando-se as diferenças nos movimentos sociais considerando: 1) as caraterísticas específicas da crise sócio económica e as suas consequências em termos de potencial de mobilização; 2) as reações políticas à crise, no que se pode definir como oportunidades políticas e ameaças; e 3) as culturas e estruturas dos movimentos sociais que caraterizam cada país (2017:2).

A conclusão comparativa (capítulo nove) apresenta uma visão transversal da miríade dos países incluída no objeto de estudo (2017:30), identificando as características dos protestos antiausteridade de cada país, ligando-se os movimentos às especificidades domésticas do neoliberalismo tardio assim como à responsabilidade política inerente.

Introduz-se e analisa-se, também, dados sistemáticos acerca do abalo socioeconómico bem como as consequências políticas da crise e discutem-se possibilidades futuras para modelos analíticos que medeiem os estudos dos movimentos sociais e a economia política, trazendo o capitalismo de volta à análise da política de contestação.

Fica de fora parte da Europa periférica, a Europa de Leste, lacuna a preencher em investigação posterior (2017: 292-293). 